\title{
The History and Significance of English Phrases Originating in China Coast Pidgin
}

\author{
Jeshua D. Noel ${ }^{1}$ \\ ${ }^{1}$ Hannibal La-Grange University, United States \\ Correspondence: Jeshua D. Noel, Hannibal-La Grange University, Hannibal MO 63401, United States. Tel: 1- \\ 573-795-6064. E-mail: jeshuadouglasnoel@gmail.com
}

Received: November 23, 2019; Accepted: December 3, 2019; Published: December 3, 2019

The research received no financing.

\begin{abstract}
China Coast Pidgin (CCP) has long been recognized by linguists as the first historical example of pidginization. However, comprehensive research regarding its impact on British and American English, has yet to be conducted. This paper serves as an introduction to the study of these concepts, exploring the etymology of words and phrases originating in $\mathrm{CCP}$, as well as analyzing its history, structure, and relationship to culture.
\end{abstract}

Keywords: Chinese Pidgin English, pidginization, creole, etymology

\section{Introduction}

Languages in the western hemisphere are often thought of as very different from those of their eastern counterparts. While it is true that syntactic structures and phonological articulations may vary greatly between such languages, the expansion of European trade networks in the $17^{\text {th }}$ and $18^{\text {th }}$ century, large-scale international conflicts throughout the $19^{\text {th }}$ and $20^{\text {th }}$, and the recent rise of ever-enveloping global communications systems have allowed those in each category to influence one another significantly. For example, a certain pidgin developed from the $17^{\text {th }}$ to the $19^{\text {th }}$ century, along the coast of China, a hub for trade with European sailors, and has left its mark on English in ways often unrecognized and perhaps unappreciated. Thanks to what is today known as China Coast Pidgin (CCP), several words and phrases, Romanized or translated, have been adopted from Chinese into the English lexicon. The phrases themselves reflect the social and political climate in which they originally traversed tongues, and have much to teach the world about human interactions during this period of economic growth and multicultural tension.

To recognize the significance of $\mathrm{CCP}$ and its influence on the English language, it is necessary first to review the historical context visible in its nature. While the words "silk" and "china" (porcelain) had already been indirectly loaned to English in 888 via Latin and Greek, it was not until the Qing Dynasty (1644-1912) that words were exchanged directly, resulting in the convergence of two languages that would one day become social superpowers (Liu and Zhang, 1816).

The direct loaning began in the seventeenth century and can be said to have influenced, not only English, but succeeding pidgins in the Pacific as well. The first English trading post in China was established in 1644 (Todd 61). This makes CCP the oldest Chinese-English pidgin to be discovered, leading eventually to its status as the "mother of all pidgins" (Ansaldo 184). One theory of origin for the word pidgin itself is a humble beginning as a Chinese mispronunciation of "business" (Todd 8). However, such distance in time leaves CCP in a position to be misunderstood.

\section{Historical Context}

Due to the "protectionist nature of the Chinese empire," (Ansaldo 184) the interactions between English and Chinese traders were initially greatly limited in setting and subject matter. With only one waterway, the Pearl River Delta, accessible to English traders, CCP was able to develop and spread quickly amongst its speakers. It was not long before this useful pidgin became the lingua franca of its region. As a result, it was written down and studied intently, which "renders it rather unique in the history of pidgin development" (Ansaldo 185). Herein lies the misunderstanding. Due to the earlier mentioned silk trade, along with other trade routes already established in Asia, China was not in desperate need of the European merchants' efforts and supplies. Instead, such merchants were merely tolerated, consequently being confined to one small area of the region specifically designated for 
trade with Westerners (the Pearl River Delta). Trading had long been considered a lowly occupation in Chinese society, leaving the Westerners to be perceived as culturally inferior (Ansaldo 187). In fact, a text written later for the instruction of Chinese citizens in CCP was titled Hungmaou mae mae tung yung kwei hwa, which translates roughly to Those Words of the Devilish Language of Red-Bristled People Commonly Used in Buying and Selling. (Bolton 43). The book consisted primarily of words and phrases relating to numbers and occupations. An earlier version was titled Language of the Red-Haired Ghost Devils (Ansaldo and Matthews 10). The cover of the pamphlet portrays a seemingly discontented European fellow. Regardless of whether the British were explicitly aware of this bias, Japan had already plainly refused their trade proposals (Bolton 188).

Because of this, the British were in a state of submission during the establishment of the Canton System, which gave Chinese authorities strict control and oversight regarding the trading operations along the China coast. Embodying these tensions, immediately before the Canton System's implementation, an English merchant named James Flint spoke with the Chinese Emperor about suspected corruption of coastal authorities. Flint was imprisoned for three years and ultimately expelled from China. It is this encounter that led the Emperor to close all ports but Canton and to forbid the teaching of Chinese to foreigners (Ansaldo190). This attitude would not change much until the mid-1800s, when the use of CCP became in China a symbol of social inferiority, and when The Instructor was published, which "attempted to make Standard English comprehensible to Chinese speakers" (Ansaldo and Matthews 11). Such circumstances suggest that, contrary to assumptions propagated by English literature, CCP was more often the result of Western merchants attempts at learning Chinese than of the Chinese trying to learn English (Ansaldo 6).

However, Western trading companies did often hire "compradors" from the area to work in trading houses or onboard ships. Many of these compradors learned to speak severely limited English, along with Portuguese (Ansaldo 191). The significance of these compradors' linguistic pursuits is that, after the Canton System collapsed, some of them began careers as independent merchants, leading to the further dissemination and utility of what was becoming CCP. (Ansaldo 192). Also contributing to the spread of CCP, and also resulting from the collapse of the Canton System, was the replacement of Chinese linguists, often accused by Western merchants of trading dishonestly, by "foreign missionaries" (Ansaldo 193).

Language is validified by use. While linguists were responsible for facilitating the formal interactions between Western and Chinese traders in the Canton system, the informal interactions with locals also contributed largely to the development of CCP. To provide a general idea of the nature of these interactions, it should be noted that one of the most notorious sentences recorded in CCP is Carei glandi hola pickenini hola?, which translates to do you want the large prostitute or the small prostitute? (Ansaldo 193).

\section{China Coast Literature}

While the travel journals of Western missionaries and merchants contain accounts of the Canton System's social elements, the matter-of-fact accounts of their illegal activity fail to reflect the full scope of life on the China Coast, especially for native residents. The Encyclopedia of Linguistics points out that, "with the exception of slender second-hand evidence from the first period of genesis, mostly in European travel accounts, almost all the data we have fall between 1836 and 1901, and, heavily anglicized, are not reliable (Strazny 200). The exception to the former rule (but not the latter) is Noble's $A$ Voyage to the East Indies, which contains the notorious phrase mentioned earlier.

One series of fictional, though accurate and meaningful, descriptions of this context came from the short stories written by Elise Eilliamina Edersheim (1860-1921). Elise was the wife of Herbert Allen Giles, "the most celebrated sinologist and linguist of nineteenth-century China" (Bolton 49) and creator the Wade-Giles system of Romanized transcription used to describe the pronunciation of Chinese syllables in Western form before the rise of Pinyin. Published under the pseudonym Lise Boehm, the short stories in China Coast Tales describe the lives, dialects, and vices of Western missionaries, customs officers, and merchants with great drama and close detail. Throughout the tales, it is made clear that fears of racial and cultural mixing were not limited to the Chinese locals. In "Dobson's Daughter," a young Eurasian girl is criticized constantly for her appearance, mannerisms, and effect on her English father's reputation. Edersheim's work suggests that each party (the English and the Chinese) thought lowly of each other, and failed repeatedly to respect each other's conventions, religions, and cultures. Edersheim explores this disconnect in the second story of China Coast Tales, "The Noble Army," in her description of English missionary literature regarding China:

"The only books, or writings, he had been furnished with were volumes upon volumes of missionary reports, missionary letters, and missionary views on heathenism in China! Very good, excellent, quite the best reading for a young recruit perhaps, but sadly insufficient, inaccurate, even misleading" (Edersheim 92) 
Edersheim represents the tension and sentiment of the average English missionary accurately. In fact, according to Kingsley Bolton's Chinese Englishes, A Sociolinguistic History, many missionaries even considered the propagation of CCP to be a "barrier set up by the Mandarin officials against the evangelism and enlightenment of China" (Bolton 153). Edersheim's work is largely unknown, especially when compared to G.H. Leland's PidginEnglish Sing-Song. This is a great misfortune, for although Leland's work brought significant attention to CCP in the western world, it also "contributed to the formation of a cultural imaginary of Chinese people at a time of growing anti-Chinese racism in the United States and Britain" (Bolton 35). Below is an excerpt from Leland's poem, 'Ping-wing,' which appears in Pidgin-English Sing-Song:

An thlowee cat in bilin' rice.

Hab chow-chow up, an' 'Now,' talk he,

'My wonda' where he meeow cat be?'

(Leland 29).

While these verses are absurdly racist, suggesting that Ping-Wing eats cats and perpetuating a stereotype that would pervade Western perceptions of Chinese culture for decades to come, they do provide a helpful example of CCP in use. One must remember that CCP was written and studied, so Leland's work is not merely his personal attempt to spell out the phonetic properties of the pidgin, but is likely based on familiarity with the alreadyestablished written form of certain words and phrases. Based on the introduction to Leland's collection of poetry, it appears that he finds CCP to be practical, useful, and interesting. Simultaneously, the remarks and circumstances throughout his book suggest a heavy bias against the Chinese people, culture, and nation. According to his own writing in the St. James Gazette, Leland claims that he was fond of the pidgin, but only as a tool for the Chinese to learn English quickly ("Chinese Pidgin"). (As discussed above, it is more likely in fact that CCP's primary function was for economically eager Englishmen to avoid learning Chinese.) Nonetheless, Leland viewed Chinese itself as primitive and archaic, as well as lacking any determinable grammar ("Chinese Pidgin").

Leland claims that the primary purpose of his blatantly racist poetry is to instruct readers in CCP, and this is somewhat evidenced by the inclusion of a small "dictionary" compiled at the back of the book. Perhaps Leland believed his crude claims to be catchy and entertaining, so that the reader would be more likely to remember what he was learning. However, if Leland believes that it is the Chinese who must learn CCP, his efforts may contradict his considerations. Would a resident of China not be offended by the passage referenced above? One would not be motivated to trade with English merchants, but to view them with even more disdain than was already prevalent throughout China.

It is possible that Leland thought himself unable to instruct the Chinese in CCP. This would be a fair conclusion, given his admitted inability to comprehend the basic components of the Chinese language ("Chinese Pidgin English."). Therefore, a reasonable course of action might be to instruct his fellow Englishmen instead. Again, the divisive nature of Leland's work poses a problem; one can imagine an Englishman whose conception of the Chinese character (here used in the philosophical, rather than philological sense) is based on Leland's claims. How could such a man desire any exchange between his lot and those of the caricatures conjured by Leland's remarks?

As an example of the, at least, linguistic value of Leland's poems, in the "glossary of Chinese" included at the end of the memoir of Aeneas Anderson, a servant to Lord Macartney (head of an embassy designed to modernize trade relations with China in 1793, whose efforts were dismissed almost as swiftly as those of the aforementioned, unfortunate James Flint) chow-chow is described as meaning "victuals or meat" (Anderson). Edersheim's story, "The Noble Army," uses the phrase in this way as well, in describing a young missionary's aversion to adopting the behaviors of his peers who have been living in China for years, and yet have failed to appreciate Chinese culture:

"This same unanswerable objection, that it was what Roman Catholic missionaries did, stood again in his way, an angel with a drawn sword, in the matter of living on Chinese chow-chow, and dispensing with foreign-nationed boys, cooks and coolies" (Edersheim 109).

\section{Structure and Etymology}

Concerning language, what is used consistently is likely to spread effectively. According to Todd's Modern Englishes, the phrase "chow-chow" had come into use in the Hawaii islands as early as 1791 (Todd 70). The presence of U.S. missionaries throughout the 1800s and the eventual declaration of Hawaii as a U.S. state in 1959 ("Annexation Of Hawaii, 1898") ensured that the phrase would establish a long life for itself in English. According to Lexico, an online dictionary powered by Oxford University, it was in the late 19th century that 'chow-chow' 
was shortened to 'chow,' ("Chow"). This shortened form is present in the common casual English phrases "chow time" (time to eat) and "to chow down" (to eat enthusiastically).

The common phrase 'chop-chop' (to make haste) has a similar origin. According to the University of Pennsylvania's online Language Log, the Chinese phrase 快快 (pinyin: kuài kuài) means 'hurry, hurry' (Mair). This is not necessarily an example of duplication, a common feature of pidgins in which a word is repeated for emphasis often enough that the repetition becomes central to the word's use itself, because the Chinese version of the phrase contains the duplicate as well. (Compare to chow-chow). It has been noted both by $19^{\text {th }}$ century scholars studying CCP, as well as contemporary authors, that one of the morphological characteristics of Chinese is the repetition of similar or associated words in the formation of new ones. R.K. Douglas, in 1888, writes on "the use of double verbs of identical or nearly identical meanings to express a single action," ("Chinese Pidgin"). He cites this as the origin of phrases in CCP such as 'look see' (meaning, look), 'topside' (a rendering of shang p'ien, literally translated), and 'one piece man' (meaning, one man).

In recent literature, Chris Shei, in Understanding the Chinese Language: A Comprehensive Linguistic Introduction, describes this phenomenon as a "coordinative" morphological relationship, in which "two elements...equal or closely related in meaning" combine to form a new word with a similar meaning (Shei). Shenlti3 (pinyin) translates literally as 'body-body' and simply means 'body,' while pin2qiong2 (pinyin) translates as 'deficientdestitute' and means 'poor' (Shei). Shei lists five other possible morphological relationships in the Chinese language. Douglas's example of 'topside' would most likely fall into one of these additional categories; namely, this word's formation would be attributed by Shei to an endocentric relationship, in which "the first element modifies the second" (Shei). Another phrase in this category would be bai2tian1 (pinyin), translated literally as 'white-day' and meaning 'daytime' (Shei). This is not unlike the process of developing compound words in English, such as football and bedrest. Here one finds, at the morphological level, the grammatical rules Leland deemed immediately undiscoverable and therefore nonexistent.

It has often been noted that CCP is structurally Chinese and lexically English ("Pidgin English in China"). On one hand, it can be observed that nearly every word recorded in the pidgin appears to be a Chinese approximation of the English pronunciation of a word with the same meaning. On the other hand, sentences in CCP often follow Chinese grammatical and syntactical rules. The Oxford English Dictionary describes CCP as "arranged according to Chinese idiom," (Oxford, 2004). Chinese idioms tend to follow rules of syllabic structure that are not often present in significant phrases in CCP. Therefore, one may assume that the Oxford's definition is appropriate, to the extent that Chinese idioms must follow the grammatical rules of Chinese. One might suppose that, like an idiom, CCP contains a familiar grammatical structure, but also words that mean nothing outside of their context (i.e. catchee).

One especially unique way in which Chinese grammatical rules affect CCP is the use of classifiers, which are used in Chinese dialects to "qualify" nouns. "One man" may become, in CCP, "one piecee man." The classifier, piecee, is used to connect the determiner, one, to the modified noun, man ("A Pidgin Case Study"). Another significant structural feature of CCP is the omission of auxiliaries ("A Pidgin Case Study"). For example, dropping the word "are" often results in phrases such as: "What you doing?" "Where you at?" and "Where you going?"

This unique combination of features has the potential to form sentences structured as such: "Why you steal? I go find one piecee officer." (Why did you steal? I will go find an officer.) Due to a number of phonological and lexical compromises, this phrase becomes: "Why you takee? I go catchee one piecee officer." [war ju: terki? ar gou kæti wan pisi 'ofəsər.] The addition of $/ \mathrm{i} /$ to the end of words is a Cantonese speech habit, used to "break up consonant clusters" (Wei). This is not only how the sentences would be pronounced, but how they would appear when written. The fact that CCP was written and, as discussed earlier, studied, affords it a unique status among pidgins.

An additional feature of CCP that contributes to its unique status is its apparent self-awareness, or at least the awareness of those using it, even early on, of its development. One English critic was already using some form of, "That must be Pidgin English for ," to dismiss claims contrary to his own in 1872 ("Eloquence"). Having lost its usefulness in Hong Kong as recently as 1960, due to "a decline of canton trade in [the] Hong Kong coastal areas," ("A Pidgin Case Study") many years of criticism and commentary would follow in the meantime.

Vicki Croke, author of The Elephant Company, described one social impact of CCP aptly in her biography, The Lady and the Panda. She claims that, "Pidgin English solved one problem, that of basic communication, while creating another, making Chinese speakers seem simpleminded." (Croke 48) However, the same might be said for direct translations of Chinese to English.

As Chris Shei observes in Understanding the Chinese Language, "Chinese is a non-inflectional, discourse-oriented language. Many grammatical elements obligatory to a language like English can often be omitted in Chinese," 
(Shei 62). He provides a variation of the following example, in which the subject and the subordinate conjunction have been omitted: 感冒时可以母乳喂养吗? (Can you breastfeed when you have a cold?)

A direct English translation may read as 'Can common cold breastfeed?' which, as Shei observes, is nonsense. Some knowledge of the grammar of each language, or at least an acknowledgement that grammatical rules vary greatly between the two, is necessary in order to appreciate the utility of CCP, given that British ships first began to appear along the coast of China three-hundred and seventy-one years before the release of Google Translate (Sommerlad).

To digress on the influence of Chinese grammar on the development of CCP, and to return to 'chop-chop,' regardless of its morphological origin, 'chop-chop' is remains a common phrase in English today. Additionally, the Sino-Indian hybrid, 'Ickoochop,' is the equivalent (Bolton 40) and perhaps the origin, of the English 'first chop,' meaning 'the best.' Derived from this phrase is another familiar English word: chopsticks. Xuan Liu and Lanqin Zhang suggest that this was likely the result of English traders "mistaking the Chinese word for chopstick, Mandarin kuaizi of kuai, with the homonym kuai" (Liu and Zhang, 1818). Because kuài had been anglicized to the word 'chop,' this suggestion is the most reasonable explanation of the English 'chopsticks.'

Some phrases developed as part of CCP and have not influenced American English. The phrase 'chin-chin' is defined in Anderson's glossary as "to supplicate or to pray" (Anderson) and by Bolton's Chinese Englishes as "to request" or "a salutation" and finding its origin in the Chinese "tsing" and "tsing ah," respectively (Bolton 154). This phrase, like 'chow-chow' is an example of duplication. Despite its absence in American English, a similar phrase, 'cin cin,' is often used as a celebratory toast in Italy and France ("English Translation Of "Cincin."). The phrase may have originated in European ports, with sailors and merchants returning from China using "chin-chin" as a greeting.

The origin of "chin-chin" has been mistakenly attributed to W.W. Rockhill's The Journey of William of Rubruck to the Eastern Parts of the World, 1253-55. Rockhill records interactions with hairy, barbaric men who say only 'chin-chin.' As amusing as his story is, this use of chin-chin is distinct from the Chinese tsing tsing, and, according to Andrew West, U.K. academic and founder of Babelstone, is more akin to xing xing (猩猩) which translates to 'orangutan' (West). There are many other words and phrases, such as lose face, no-can-do, and long-time-no-see, that are of common use English and have their origins in CCP.

\section{Conclusion}

The use of China Coast Pidgin declined in the $20^{\text {th }}$ century, largely as a result of English instruction and Hong Kong's conversion to "a modern, Anglo-Chinese bilingual (and bicultural) identity (Ansaldo, 197). However, like the loanwords and phrases exchanged between Chinese and English before and after the era of CCP, the surviving phrases from this ecosystem have permanently influenced the English language. Further research might include a deep dive into the island of Nauru, the one country in which CCP can still be found in common use, as well as a more comprehensive analysis of how the linguistic structure of Chinese might have impacted the development of $\mathrm{CCP}$, using other pidgins with Chinese elements as a development in the search for commonalities. Furthermore, wider recognition and study of the works of Edersheim and commentaries on CCP by Chinese citizens is necessary. The significance of CCP demonstrates that people will make compromises to communicate. It also suggests that they are nearly guaranteed to misunderstand each other along the way. The mother of all pidgins reminds one strikingly that the study of the language is often the study of people, their decisions, and their lives.

\section{References}

Annexation of Hawaii. (1898). 2001-2009. State. Gov, 2019. Retrieved from https://20012009.state.gov/r/pa/ho/time/gp/17661.htm

Anderson, A. (1794). A Narrative of the British Embassy to China in the Years 1792, 1793, and 1794; Containing the Various Circumstances of the Embassy; with Accounts of the Customs and Manners of the Chinese. The Second Edition. Printed for J. Debrett, 1795.

Ansaldo, U. (2013). Contact Languages: Ecology And Evolution In Asia. Cambridge University Press, 2013.

Ansaldo, U., \& Stephen, M. (2010). China Coast Pidgin: Texts And Contexts. Pidgins and Creoles in Asian Contexts, 25(1), 63-94. John Benjamins Publishing Company. https://doi.org/10.1075/jpcl.25.1.03ans

Bolton, K. (2000). Language And Hybridization: Pidgin Tales From The China Coast. Interventions, 2(1), 35-52. Informa UK Limited. https://doi.org/10.1080/136980100360788

Bolton, K. (2006). Chinese Englishes: A Sociolinguistic History. Cambridge University Press.

Chinese Pidgin English. The London and China Telegraph, July 14, 1888, pp. 17. Newspaper Archive. Accessed 
28 Oct. 2019.

Chinese Pidgin English. Yes! Chinese Blog, 28 Jan. 2010. Retrieved from http://leelaan.wordpress.com/2009/11/18/chinese-pidgin-english/

Chow | Definition Of Chow by Lexico. Lexico Dictionaries | English, 2019, https://www.lexico.com/en/definition/chow

Croke, V. (2005). The Lady and the Panda. Random House.

Edersheim, Elise Williamina. (1897). China Coast Tales.

"Eloquence in the Straits" The London and China Telegraph, Sept. 2, 1872, pp. 612. Newspaper Archive. Accessed 16 Nov. 2019.

"English Translation of "Cincin" | Collins Italian-English Dictionary". Collinsdictionary. Com, 2019. https://www.collinsdictionary.com/dictionary/italian-english/cincin.

Leland, Charles Godfrey. Pidgin-English Sing-Song: or, Songs and Stories in the China-English Dialect, with a Vocabulary. J. B. Lippincott \&amp; Co., 1876.

Liu, X., \& Zhang, L. Q. (2011). On Chinese Loanwords In English. Theory And Practice In Language Studies, 1(12), 1816-1819. https://doi.org/10.4304/tpls.1.12.1816-1819

Mair, V. (2019). Chop-Chop And Chopsticks. Language Log. https://languagelog.ldc.upenn.edu/nll/?p=8671

Oxford English Dictionary. (2004). Oxford University Press.

A Pidgin Case Study: Chinese Pidgin English. Language Contact. Retrieved from https://sites.google.com/site/hongkonglinguistics/Downhome/Topic4/apidgincasestudychinesepidginenglish

Pidgin English in China. The Chinese Pidgin English Language. Retrieved from http://www.chinasage.info/pidginenglish.htm

Ruysbroeck, Willem van, \& William Woodville Rockhill. (2010). The Journey of William of Rubruck to the Eastern Parts of the World, 1253-1255.

Shei, C. (2014). Understanding the Chinese Language: A Comprehensive Linguistic Introduction. Routledge. https://doi.org/10.4324/9781315767222

Sommerlad, Joe (June 19, 2018). Google Translate: How does the search giant's multilingual interpreter actually work? Independent. Accessed November 19, 2019.

Stavorinus, J. S. A. (1762). Voyage to the East Indies In 1747 And 1748 ... Printed For T. Becket and P. A. Dehondt And T. Durham.

Strazny, P. (2013). Encyclopedia of Linguistics. Taylor and Francis.

Todd, L. (1989). Modern Englishes. Blackwell.

Wade-Giles Romanization | Chinese Language. Encyclopedia Britannica, 2019. Retrieved from http://www.britannica.com/topic/Wade-Giles-romanization

Wei, F. L. (2017). Chinese Pidgin English: Unravel Magazine. Unravel. Retrieved from http://unravellingmag.com/articles/chinese-pidgin-english

West, A. (2019). Babelstone Blog: Chimps With Clogs. Babelstone. Co. UK. Retrieved from http://www.babelstone.co.uk/Blog/2006/05/chimps-with-clogs.html

\section{Appendix A}

Common English words and phrases known to have their origin in China Coast Pidgin

No can do, long time no see, chop-chop, first-chop (British English), chopsticks, chow-chow (chow), chin-chin (common toast/greeting in Europe, especially Italy and Spain), pidgin, cash (originally spelled 'casse,' referred to Chinese coins), Mandarin, junk (originally referred to small boats - origin of current use of the word 'junk' is considered unknown), bamboo, catty, to make do, no pain no gain, chicken fried rice, no-go, 'where to?,' looksee, look see man (1920's American English term for 'tourist'), 'how come?,' topside. 


\section{Copyrights}

Copyright for this article is retained by the author(s), with first publication rights granted to the journal.

This is an open-access article distributed under the terms and conditions of the Creative Commons Attribution license (http://creativecommons.org/licenses/by/4.0/). 